\title{
Educação a distância compulsória: reflexões para o ensino de enfermagem na pandemia de COVID-19
}

\author{
Compulsory distance education: reflections for nursing education in the COVID-19 pandemic \\ Educación a distancia obligatoria: reflexiones para la educación en enfermería en la pandemia
}

COVID-19

Fabio Scorsolini-Comin ORCID: http://orcid.org/0000-0001-6281-3371

Universidade de São Paulo, Brasil

E-mail: fabio.scorsolini@usp.br

Lucas Rossato

ORCID: http://orcid.org/0000-0003-3350-0688

Universidade de São Paulo, Brasil E-mail: rossatousp@usp.br

Lucas Pereira de Melo

ORCID: http://orcid.org/0000-0001-8392-1398

Universidade de São Paulo, Brasil E-mail: 1pmelo@usp.br

Ronan da Silva Parreira Gaia ORCID: http://orcid.org/0000-0003-2342-0019

Universidade de São Paulo, Brasil

E-mail: ronangaia@yahoo.com.br

\begin{abstract}
Resumo
O objetivo desta reflexão teórica é discutir de que modo a educação a distância (EAD) tem sido implementada como metodologia capaz de possibilitar a manutenção dos processos de ensino e aprendizagem em função da pandemia de COVID-19 a partir do ano de 2020, tendo como referência os cursos de graduação em enfermagem. Nesta reflexão, apresentam-se as potencialidades e fragilidades da EAD quando utilizada como modelo substitutivo ao ensino presencial. Para tanto, refletiu-se sobre o conceito de EAD, sua utilização na formação profissional em enfermagem, as disputas em torno desta utilização e, por último, apresentou-se uma reflexão crítica fundamentada na literatura e nas experiências dos autores como docentes ministrantes de disciplinas em formato "não presencial" em resposta à pandemia da COVID-19. As discussões em relação a esse problema se mostraram teoricamente pertinentes e possibilitaram elencar e refletir as materialidades e performances produzidas nas experiências discente e docente no período da pandemia.
\end{abstract}

Palavras-chave: Ensino; Educação a distância; Educação em enfermagem; COVID-19.

\begin{abstract}
The aim of this theoretical reflection is to discuss how distance education (DE) has been implemented as a methodology capable of enabling the maintenance of teaching and learning processes due to the COVID-19 pandemic from the year 2020, having as reference the undergraduate courses in nursing. In this reflection, the strengths and weaknesses of distance learning when used as a substitute model for on-site teaching are presented. Therefore, the concept of DE was reflected on, its use in professional training in nursing, the disputes around this use and, finally, a critical reflection based on the literature and on the authors' experiences as teaching professors of disciplines was presented. in "off-site" format in response to the COVID-19 pandemic. Discussions regarding this problem proved to be theoretically relevant and made it possible to list and reflect the materialities and performances produced in the student and teacher experiences during the pandemic period.
\end{abstract}

Keywords: Teaching; Distance education; Nursing education; COVID-19.

\section{Resumen}

El objetivo de esta reflexión teórica es discutir cómo la educación a distancia (EAD) se ha implementado como una metodología capaz de posibilitar el mantenimiento de los procesos de enseñanza y aprendizaje debido a la pandemia COVID-19 a partir del año 2020, teniendo como referencia los cursos de grado en enfermería. En esta reflexión, se presentan las fortalezas y debilidades de la educación a distancia cuando se utiliza como modelo sustituto de la enseñanza presencial. Por tanto, se reflexionó sobre el concepto de EAD, su uso en la formación profesional en enfermería, las disputas en torno a este uso y, finalmente, se presentó una reflexión crítica a partir de la literatura y de las experiencias de los autores como profesores docentes de disciplinas. fuera del sitio"en respuesta a la pandemia 
de COVID-19. Las discusiones sobre este problema resultaron ser teóricamente relevantes y permitieron enumerar y reflejar las materialidades y desempeños producidos en las experiencias de estudiantes y docentes durante el período pandémico.

Palabras clave: Enseñanza; Educación a distancia; Educación en enfermería; COVID-19.

\section{Introdução}

O presente estudo apresenta-se como uma reflexão acerca da educação a distância (EAD) no contexto da pandemia de COVID-19, em consonância com uma literatura, sobretudo internacional (Chick et al., 2020; Warhadpande et al., 2020), que vem sendo produzida como forma de ampliar conhecimentos para uma discussão em torno dos processos formativos no campo da saúde (Bezerra, 2020; Jowsey et al., 2020). Como esta reflexão foi produzida no período em que a pandemia ainda está em curso, a exemplo dos estudos em veiculação, há que se destacar seu caráter aberto e não definitivo, de modo que se situa nesse ir-e-vir que tem marcado cada fase da pandemia em termos das adaptações e dos itinerários possíveis nesse cenário.

Em que pesem as diferentes condições e respostas à pandemia apresentadas pelos países e seus governos, os processos educacionais permeiam tanto a discussão sobre as atividades presenciais que tiveram que ser interrompidas em função do potencial de transmissão do vírus quanto a retomada das mesmas em países e regiões que estão com curvas de contágio em declínio ou com uma gestão mais adequada em termos de saúde pública, diminuindo os possíveis agravos à saúde decorrentes da retomada, por exemplo, das aulas presenciais. A educação, desse modo, tem se colocado no centro de um debate (Dias \& Pinto, 2021) que não apenas convoca as inteligibilidades da área de saúde, mas também da política e da economia, representando um dos setores mais afetados pela pandemia e, igualmente, com um maior número de respostas produzidas em função dessas condições impostas, no contexto brasileiro, a partir de março de 2020.

A presente reflexão surge de debates realizados entre profissionais da educação superior de diferentes formações no campo das ciências humanas e da saúde. Essa fala localizada nestes campos do saber, mais do que circunscrever posicionamentos, permite compartilhar reflexões e debates que estão sendo produzidos frente à pandemia, permitindo endereçamentos que podem ser úteis a pesquisadores, gestores e outros profissionais da educação e da saúde. Esse posicionamento é de suma importância para que se possa pensar na educação a partir de uma vertente endoperspectivada, permitindo a construção de inteligibilidades que respeitem as experiências, os itinerários e as reflexões produzidas em resposta à pandemia e aos ajustes que foram incorporados ao cotidiano educacional, bem como as adaptações que ainda serão necessárias até a chamada retomada total das atividades de ensino presencial.

Considerando os aspectos a serem abordados, é preciso realizar inicialmente um resgate histórico em relação à temática principal em debate, a EAD, para que se possa situar as reflexões realizadas diante do atual contexto vivido. Deste modo, pretende-se refletir sobre uma modalidade de ensino já existente no mundo e no Brasil, mas que ganhou maior destaque em decorrência da pandemia da COVID-19. Como discutiremos no decorrer deste artigo, também pretende-se refletir sobre o papel da enfermagem nesse contexto, haja vista a tradição da EAD aplicada a esse campo do conhecimento em saúde.

Nas últimas décadas a EAD vem ganhando espaço diante da intensa globalização e criação de tecnologias inovadoras, sendo conceituada como um processo educativo sistemático que permite o estudo individual ou em grupo por meio de tecnologias, exigindo múltiplas vias de comunicação entre os participantes (Grossi \& Kobayashi, 2013). No Brasil, a EAD tem alcançado impulso e expressão política com a Lei de Diretrizes e Bases da Educação Nacional (Lei Federal n. 9.394, de 20 de dezembro de 1996) na qual figura como modalidade regular integrante do sistema nacional de educação (Oliveira, 2007).

Com o passar dos anos, a EAD consolidou-se como uma das estratégias que buscam atender às necessidades sociais da universalização do acesso à educação, não apenas ao ensino superior (Alves et al., 2015), mas também à educação de jovens e adultos, como ficaram conhecidos os cursos por correspondência (Instituto Universal Brasileiro) e pela TV (Telecurso 2000, da Fundação Roberto Marinho), bastante populares nas décadas de 1980 e 1990 no Brasil (Scorsolini-Comin, 2013). Assim, é 
importante considerar que a EAD não se resume apenas às mais recentes tecnologias digitais de informação e comunicação, mas abrange diversos recursos comunicacionais que permitam a corporificação dos processos de ensino e aprendizagem, tais como a TV, o que também deve ser considerado tendo em vista os diferentes cenários econômicos e sociais em tela.

Para além das iniciativas voltadas à alfabetização e à formação técnica para o mercado de trabalho, o Brasil tem se destacado como um dos países nos quais a EAD tem se expandido rapidamente, sobretudo na formação de recursos humanos no campo da saúde. A EAD se faz presente em cursos híbridos e integralmente a distância, em ações ligadas à graduação, à pós-graduação (lato sensu, stricto sensu e treinamentos em serviço, como as residências em saúde) e à educação permanente em saúde, havendo uma grande diversidade de estratégias e iniciativas que acenam para a irreversibilidade da EAD no contexto da formação e da educação no campo da saúde brasileira. Um exemplo de como a EAD tem sido empregada na formação complementar de profissionais de saúde pode ser observado no Sistema Universidade Aberta do SUS (UNA-SUS), criado em 2010 para atender às necessidades de capacitação e educação permanente dos profissionais que atuam no Sistema Único de Saúde (SUS) e que oferece cursos na modalidade EAD ministrados por universidade federais de todo o país.

Com a pandemia de COVID-19 no início de 2020, as discussões sobre a implementação da EAD de forma mais ampla foram revisitadas (Bezerra, 2020), considerando um cenário no qual a EAD deixava de ser uma possibilidade e passou a ser, muitas vezes, uma das vias para a continuidade de alguns processos de formação. Destacam-se aqui a polissemia e as disputas de sentidos em torno da EAD que o contexto da pandemia tem suscitado ou acirrado. Um indicador desses processos é a utilização de termos como "ensino não presencial", "ensino remoto", "ensino emergencial", "ensino remoto emergencial" e "ensino virtual" em detrimento da já consagrada EAD. Em que pese a importância de distinguir esses termos, muitas vezes tomados como sinônimos, também se recupera a necessidade de problematizar em que medida essas expressões também passaram a ser (re)produzidas na tentativa de distanciamento em relação à EAD e aos sentidos evocados por essa sigla no contexto educacional brasileiro (Scorsolini-Comin et al., 2020).

A partir dessas considerações, este artigo tem por objetivo refletir sobre o modo por meio do qual a EAD foi e tem sido sugerida ou implementada como metodologia capaz de possibilitar a manutenção dos processos de ensino e aprendizagem em função do distanciamento social deflagrado como recomendação para a contenção da transmissão viral a partir da pandemia de COVID-19. Para tanto, tomou-se como referência os cursos de graduação em saúde, particularmente os de enfermagem. Esta reflexão será orientada pelo diálogo entre a produção científica na área de EAD e as experiências produzidas pela área de saúde acerca do emprego dessas metodologias na formação dos profissionais de nível superior.

\section{Método}

Trata-se de uma reflexão teórica que busca analisar como fenômeno principal o ensino superior no contexto da pandemia da COVID-19. Esse fenômeno, aqui, é discutido principalmente a partir dos paradigmas da EAD, tensionando também o uso de termos como o ensino remoto, o ensino remoto emergencial e o ensino híbrido, apenas para citar alguns exemplos que foram sendo apropriados pelo ensino superior brasileiro durante a pandemia. Esta reflexão é apresentada em forma de ensaio, dialogando com evidências disponíveis em estudos científicos e também considerando a experiência dos autores no ensino superior, especificamente no campo da enfermagem. A formação superior em enfermagem, neste ensaio, é empregada como contexto de referência, o que se justifica tanto em termos educacionais, haja vista os impactos da pandemia na formação desses profissionais, como em termos da relevância social desse fazer no cenário das ciências da saúde (Ribeiro et al., 2022). A esses elementos acrescenta-se o fato de que a formação superior em enfermagem, mesmo antes da pandemia, já era um dos cursos que mais diretamente discutiam os limites e as possibilidades da EAD para a formação desses profissionais. Como se trata de um fenômeno ainda em trânsito e cuja publicação de evidências tem ocorrido a partir de 2020, com a deflagração da pandemia da COVID-19, as reflexões aqui apresentadas assumem uma estrutura mais descritiva, buscando 
dialogar com dados de investigações veiculadas no trânsito pandêmico, mas também recuperando estudos mais tradicionais, sobretudo para a caraterização da EAD. A reflexão teórica caracteriza-se por ser um método de pesquisa que permite problematizar, discutir, refletir e dialogar a respeito do estado atual de um determinado tópico em questão fazendo interlocuções com outras publicações científicas da área que abordem o mesmo assunto. Esse tipo de estudo marcadamente qualitativo tem por objetivo realizar questionamentos e indicar possíveis caminhos para análise crítica de fenômenos de ordem sociocultural, políticos e/ou psicológicos em voga em determinado contexto histórico (Scorsolini-Comin, 2021).

\section{EAD e a Pandemia de COVID-19}

Em 31 de dezembro de 2019, o mundo viu-se diante do anúncio de existência de um novo vírus produtor de infecções em humanos. Tratava-se do Coronavírus (Severe Acute Respiratory Syndrome Coronavirus, SARS-CoV-2), agente etiológico da COVID-19, cujos primeiros casos foram identificados em Wuhan, região central da China. Em 30 de janeiro de 2020, a Organização Mundial da Saúde (OMS) afirmou que o surto da doença era uma Emergência de Saúde Pública de Importância Internacional, o que colocou o mundo sob alerta (PAHO, 2021). Com a rápida disseminação dos casos em todo o mundo, em 11 de março a OMS caracterizou a COVID-19 como uma pandemia (PAHO, 2021), o mais importante fenômeno de saúde do século XXI devido às suas ainda imprevistas ressonâncias nos próximos anos e décadas.

Com a deflagração da pandemia, governantes e autoridades sanitárias passaram a estimular a medidas protetivas como forma de evitar a expansão do vírus. Essas decisões político-sanitárias ao redor do mundo "chegaram" ao Brasil em março de 2020, na semana em que se registrou a primeira morte confirmada oficialmente por COVID-19, o que levou as autoridades sanitárias a adotar o distanciamento social como estratégia de enfrentamento da doença. No início de agosto de 2020, o país já contabilizava mais de 100.000 óbitos decorrentes de complicações da COVID-19 e mais de três milhões de pessoas infectadas. Com o passar dos meses a situação pandêmica do país ficou complexa e cada vez mais alarmante, sobretudo pelas diferenças notadas em comparação ao comportamento da epidemia em outros países. O ano de 2021 marcou o início da vacinação em massa de nossa população, fazendo com que os números de óbitos e novas infecções declinassem, sobretudo no segundo semestre do ano. Em 05 de Janeiro de 2022 o país contabilizava 619.384 óbitos, segundo o Conselho Nacional de Secretários da Saúde - CONAS (2021), com sinais de um progressivo aumento no número de novos casos de pessoas infectadas após a flexibilização das medidas de distanciamento social adotadas no final do ano de 2021 e com a proliferação da variante ômicron. Como apontam esses números, a pandemia tem revelado grande instabilidade, de modo que acompanhar o seu progresso é uma tarefa perene no campo científico.

No setor educacional, após o início da pandemia as repercussões das medidas sanitárias adotadas logo ganharam relevo e introduziram a EAD como resposta possível na visão de alguns governantes e gestores educacionais. A EAD, deste modo, passou a ser utilizada no cenário da educação superior, no Brasil e no mundo, para transmissão de conteúdos didáticos, devido à impossibilidade das aulas ocorrerem na modalidade presencial durante o período de maior fragilidade e risco de infecção pelo vírus, no qual recomendava-se que todos estivessem em quarentena e em isolamento, com exceção dos serviços considerados essenciais (Bezerra, 2020; Chick et al., 2020; Jowsey et al., 2020; Warhadpande et al., 2020).

Em 2021, com a melhoria do cenário sanitário e avanço da vacinação em diversas partes do mundo, diversas atividades presenciais na educação básica e na superior puderam ser retomadas. No entanto, algumas atividades não presenciais continuaram mesmo com a retomada presencial. A EAD, desse modo, foi e tem sido uma resposta adotada nos mais diferentes países e em todos os níveis de ensino.

Embora a EAD seja uma modalidade de ensino já consolidada no Brasil, inclusive com números expressivos em termos de matrículas em cursos de graduação e de pós-graduação a distância, a utilização das suas metodologias se intensificou em resposta a um cenário no qual o contato físico presencial foi e permanece evitado e desaconselhado por chefes de Estado e 
autoridades sanitárias. O que se observa, em alguns contextos institucionais, é a opção pela EAD por meio de um esvaziamento de seu próprio sentido pedagógico. Em discursos oficiais e institucionais, a EAD parece ter sido tomada apenas por um de seus termos: "distância"; um substantivo que, dentro das metáforas bélicas (Sontag, 1984) utilizadas para descrever a guerra travada pela sociedade contra um inimigo "invisível", um vírus e a doença que ele provoca, vem ganhando contornos e materialidades diversas ao redor do mundo.

Nessa "guerra contra o vírus", a EAD despontou como uma variável que auxiliaria ao equacionamento do problema posto aos gestores educacionais: como manter as atividades de ensino diante do imperativo do distanciamento social? $\mathrm{Na}$ contramão do otimismo governamental e institucional, a discussão em torno da EAD durante a pandemia tem suscitado problemas e destacado os recursos mínimos para sua execução com qualidade, alguns desses já relatados na literatura: acesso à internet, acesso a ferramentas de comunicação, construção de estratégias de ensino e aprendizagem adaptadas a esse modelo, acompanhamento dos alunos nessa modalidade, bem como efetividade dessas estratégias para a formação em saúde (Magalhães, 2021; Tanaka et al., 2017). O conhecimento dessas problemáticas serviram de base para que muitas universidades públicas brasileiras suspendessem temporariamente as aulas presenciais ou mesmo os semestres letivos em 2020, sem oferecimento de atividades remotas, enquanto parte delas optaram por continuar as atividades de ensino na modalidade "não presencial". Atualmente estas atividades vêm sendo retomadas gradualmente pelas Instituições de Ensino Superior.

No contexto brasileiro, a opção pela manutenção ou não das atividades de ensino a partir da EAD não pode ser apartada de uma discussão social premente, uma vez que os cenários de desigualdade no país refletem-se nos diferentes modos como os recursos da EAD têm sido empregados ou escamoteados. Esse movimento em relação a disponibilização do ensino não presencial apenas para uma parcela dos estudantes revela um problema social brasileiro de longa data, que é a inequidade aos serviços de educação ou o abandono do ensino (Magalhães, 2021). O acesso à internet de banda larga, por exemplo, tem limitado muitos estudantes a manterem suas atividades durante a pandemia, além do acesso a equipamentos que permitam esse estudo. Consequentemente os estudantes mais afetados são aqueles que já se encontram em desvantagens de oportunidades em razão de condições econômicas e sociais (Castioni et al., 2021). Assim, não se trata de pensar em uma adaptação que leve em conta apenas uma discussão educacional, de didática e de estratégias de ensino e aprendizagem, mas, sobretudo, tendo como referência as condições sociais e econômicas que balizam a educação no Brasil.

Tem-se apontado que um equívoco existente nessa utilização da EAD é o de compreendê-la como uma alternativa à educação presencial, ou seja, como se fosse uma resposta que permitisse unicamente a continuidade dos estudos em um cenário atípico representado pela emergência da pandemia. Talvez por isso as ressalvas e evitações no uso do termo EAD, o que poderia destacar seu caráter contingencial no cenário da pandemia de COVID-19 e a demarcação do posicionamento contrário de muitas instituições de ensino relativo à ampliação dessa modalidade de ensino nos cursos superiores no Brasil, com franco protagonismo e interesse da iniciativa privada.

A EAD possui metodologias e ferramentas específicas em termos do desenvolvimento dos processos de ensino e aprendizagem que estão sendo evocadas na contemporaneidade para que muitos processos educativos, sobretudo os de estudantes da área de saúde, considerados prioritários como futuros recursos humanos para as "linhas de frente" no combate à COVID-19, não sejam interrompidos no momento de distanciamento social. Nesse contexto, estudantes, docentes e órgãos de representação desses segmentos (sindicatos, associações e sociedades científicas, diretórios centrais de estudantes, etc.) têm chamado atenção para o fato de que a simples transposição de atividades presenciais para modelos não presenciais coloca uma problemática bastante complexa, justamente por desconsiderar as diversas possibilidades que emergem da utilização da EAD em suas máximas potencialidades, o que requer recursos tecnológicos e preparação pedagógica de docentes, estudantes e materiais didáticos adequados.

O que se pode assinalar, nesse trânsito pela pandemia, é que as dificuldades ou os entraves para a execução da EAD 
são posicionadas ora como relacionadas aos alunos, ora aos professores, ora às características do próprio trabalho docente, ora em termos da comunicação entre professores e alunos, além de outras possibilidades (Ribeiro, Rossato, \& Scorsolini-Comin, 2021). A experiência docente e os diálogos estabelecidos com estudantes até o momento têm demonstrado que, apesar de ser uma alternativa viável, ainda não atende a todas as necessidades educacionais que são necessárias em condições específicas de ensino, principalmente em cursos da área da saúde e que requerem aulas e outras atividades práticas de ensino.

Nesse sentido, a reflexão sobre a pandemia levada a cabo nas ciências sociais, nomeadamente na antropologia, é de fundamental importância, pois fenômenos considerados globais - como o próprio conceito epidemiológico de pandemia já sugere (Rouquayrol, 2003) - são performados em contextos locais (Segata, 2020). Isto significa que as diferentes manifestações e os quadros sociais e sanitários produzidos pela pandemia ao redor do mundo não podem ser tomados de forma homogênea, haja vista o vírus atingir pessoas concretas, com suas histórias de vida, submetidas a processos de vulnerabilização em variados graus, com experiências espaciais e de moradia distintas. Tudo isso em bairros, cidades, estados, países, regiões e continentes nos quais as desigualdades sociais incidem de forma a configurar condições de vida, de saúde, de trabalho, de moradia e de acesso a serviços e bens significativamente peculiares.

Da mesma forma, observa-se em algumas instituições de ensino superior que optaram pela continuidade das atividades de ensino de forma "não presencial" (leia-se EAD precarizada) a desatenção as materialidades que elas constroem no âmbito institucional (por exemplo, as peculiaridades dos cursos, das unidades de ensino, da comunidade acadêmica, etc.). Há que se destacar que tais circunstâncias subestimaram alguns aspectos, tais como: desconhecimento do paradigma da EAD, desconhecimento ou falta de manejo adequado em relação a tecnologias empregadas nessa modalidade de ensino e dificuldade de acesso a tecnologias e formação adequada na área - da parte dos professores; e dificuldade de acesso à internet de banda larga e a computadores e outros dispositivos, as condições de moradia, as relações e dinâmicas familiares - da parte dos alunos. Por isso, é preciso problematizar os usos da EAD em tempos de pandemia de COVID-19 para além da transposição.

\section{A EAD para Além da Transposição}

Um dos aspectos centrais da argumentação desenvolvida na presente reflexão refere-se à transposição da educação presencial para a EAD devido à necessidade de distanciamento social imposta pela pandemia. Há que se considerar nas análises o caráter contingencial e inesperado dos impactos da pandemia nas relações sociais, em geral, e no setor educacional, em particular. Em todo caso, da parte de algumas instituições de ensino superior, nomeadamente as públicas, não faltam discursos otimistas, cheios de triunfalismos e altruísmos.

Este aspecto é interessante, tendo em vista a maneira como a EAD se colocou, como indicado anteriormente, como uma saída emergencial e possível de equacionar os problemas colocados pelo imperativo da quarentena. É importante notar algumas ambiguidades: primeiro, sua entrada em campos discursivos e de práticas, onde antes era quase impedida; segundo, a dupla função de manter distantes ou distanciadas as pessoas, ao mesmo tempo permite estar "em contato". Exemplos desses "contatos" como desdobramentos do distanciamento social no trabalho docente universitário são as reuniões administrativas, pedagógicas, de pesquisa e extensão que se multiplicam em um ritmo e em uma velocidade que parecem imitar a própria curva epidêmica da pandemia. De igual monta, assim como o excesso de trabalho era bastante criticado no modelo presencial, tais apontamentos parecem migrar também para os modelos de trabalho remoto, repercutindo em maior suscetibilidade ao adoecimento tanto de docentes como de estudantes, conforme observado na literatura científica (Freitas et al., 2021; Patias et al., 2021; Santos et al., 2021; Scorsolini-Comin et al., 2021).

Nesse sentido, quando se trata da transposição, acena-se para a EAD como uma modalidade substitutiva à presencial. Primeiramente, a ideia de transposição traz a conotação de que o ensino presencial e a EAD possuiriam objetivos distintos, colocando-se como uma possibilidade que se apresenta quando a educação presencial não pode ser realizada, em uma ideia 
próxima à de uma alternativa. Essas concepções são bastante problemáticas quando confrontadas com os princípios pedagógicos da EAD, os quais consistem no "uso de diversas linguagens, design instrucional interativo, centralização do processo na atividade do aluno, horizontalidade entre alunos e professores como fonte de conhecimento e adequação entre o conteúdo e a mídia disponibilizada aos estudantes" (Sartori, 2002, p. 7).

A transposição de conteúdos não pode ser pensada simplesmente como uma aplicação de um determinado componente curricular em um contexto diferente. O equívoco reside na tentativa de apenas transpor conteúdos de um modelo a outro, sem os devidos ajustes e sem reflexões mais aprofundadas que possam, de fato, considerar que os processos de ensino e de aprendizagem podem se dar de modos distintos, inclusive com diferentes potencialidades de aquisição e de apropriação desse conhecimento.

Considerar que os estudantes aprendem do mesmo modo a partir de modelos presenciais e de modelos a distância acaba se tornando um equívoco no sentido de que esses modelos nos convidam continuamente a diferentes posicionamentos, produzindo comportamentos e respostas distintos não apenas a partir dos estímulos propostos, mas, sobretudo, a partir das premissas e dos organizadores de cada um desses sistemas. Como se tratam de modelos distintos, que operam com inteligibilidades que nem sempre podem ser aproximadas, inclusive em termos do que é a aprendizagem, do que é interação e de quais são os resultados educacionais esperados, há que se destacar a necessidade de que tais aspectos sejam cotejados não apenas nas análises empreendidas, mas também nas comparações, o que nos coloca contrários à ideia da transposição, subjugando as potencialidades de ambos os modelos.

Além disso, a transposição precisa ser problematizada a partir do perfil dos estudantes que ingressaram, nas últimas duas décadas, no ensino superior público em decorrência das políticas de ação afirmativa que instituíram mecanismos mais equânimes no acesso à universidade. Tais ações afirmativas mudaram "a cara" da universidade pública brasileira tanto em termos de pertencimentos sociais, raciais e outros. Mas essas ações não podem ser compreendidas como suficientes quando pensamos no conceito de interseccionalidade e como esses marcadores são corporificados em função da pandemia, promovendo desigualdade e vulnerabilidade ainda que pessoas outrora excluídas da universidade hoje possuam acesso a esses espaços (Gaia et al., 2021).

Tal cenário reclama ainda mais um olhar atento às realidades locais em cada instituição, uma vez que já não é possível considerar que todos os estudantes compõem estratos sociais médio e alto, como no período anterior às ações afirmativas para pessoas oriundas de classes populares, de escolas públicas e autodeclaradas pardas, pretas e indígenas. A partir desses apontamentos, pode-se afirmar que que a noção de transposição de modelos a partir da mediação de uma tecnologia que possibilite a manutenção do que é considerado tradicional no modelo presencial acaba esvaziando a EAD, retirando-lhe as potencialidades para fazer frente aos desafios educacionais instaurados pela pandemia.

Tendo isso em vista, realizar a transposição do ensino presencial ao "não presencial" pode implicar na produção ou aprofundamento de situações de iniquidades sociais para muitos estudantes. Um ponto nevrálgico nessa discussão é o acesso à internet como requisito sine qua non ao engajamento nessa modalidade de ensino. Acessar a internet requer uma estrutura que não é sempre encontrada no contexto nacional, pois, para tal, é necessário possuir um computador ou notebook, uma instalação elétrica e poder arcar financeiramente com o gasto derivados do uso dos mesmos (Vieira \& Teo, 2018). Além disso, é preciso informação básica que permita ao usuário saber processar e interpretar, operar o objeto eletrônico em questão e utilizar a internet, tal como interpretar o que nela é possível encontrar. Em revisão elaborada por Vieira e Teo (2018), estudos mostram certa deficiência do acesso à internet, voltando-se especificamente aos estudantes cursistas da área da saúde.

Em tempos de pandemia não basta ter boas condições de conectividade. Pensando no atual perfil de estudantes universitários brasileiros (e aqui vale incluir aqueles de instituições privadas e filantrópicas que acessam por bolsas ou financiamento estudantil), é mister também refletir sobre as condições de moradia e de vida, algo que já vem sendo 
amplamente divulgado na mídia. Nesse sentido, fala-se não só das condições físicas, número de cômodos, número de pessoas residentes no domicílio, mas, sobretudo, as relações e dinâmicas sociais engendradas no interior da casa e na vizinhança. Ou seja, urge pensar sobre a relevância da situação material e relacional da moradia na configuração de espaços propícios para o estudo.

Do ponto de vista do trabalho docente, as surpresas e dificuldades também se avolumam. Nas experiências docentes é possível observar uma nítida preferência por atividades sincrônicas. Na EAD há ferramentas síncronas, nas quais o processo de ensino-aprendizagem e a interação professor-estudante se dão ao mesmo tempo; e assíncronas, aquelas em que professores e estudantes se encontram em tempos - e espaços - distintos no processo de ensino e aprendizagem.

$\mathrm{Na}$ experiência produzida pela recente pandemia, as ferramentas síncronas têm sido privilegiadas como forma de possibilitar algum contato entre alunos e professores, justamente pela imposição do isolamento social. O que, por outro lado, lança luz na imediatez da transposição do presencial para o "não presencial", com prejuízos na formação docente para atuação nessa "nova modalidade" de ensino. Além disso, a preferência pelas atividades sincrônicas desvela implicações desse processo nas temporalidades do trabalho docente, notadamente em sua etapa de planejamento.

A formação docente universitária tem duas dimensões: uma, técnico-científica-profissional; e outra, didáticopedagógica. Em se tratando da transposição do ensino presencial - para a qual a maioria dos docentes é preparada - para o "não presencial", a dimensão didático-pedagógica ganha destaque. Nesse sentido, pensar as temporalidades constitutivas dessa formação e da preparação para o ensino é de extrema relevância, uma vez que muitos docentes se viram diante do desafio de adaptar suas atividades em disciplinas de graduação e de pós-graduação, tradicionalmente oferecidas de forma presencial, para a modalidade "não presencial". Neste ponto, a EAD se colocou mais como uma incógnita na equação do trabalho docente diferente do papel naquela equação posta aos gestores educacionais.

O cenário eviscerou, portanto, não um déficit de conhecimento dos docentes, pois estes, em sua maioria, não foram formados e contratados para a EAD, mas o degrau atropelado no afã de oferecer respostas rápidas e efetivas cujo objetivo era produzir uma ideia, forçada, de continuidade do cotidiano universitário (Ribeiro et al., 2021). Como um efeito colateral dessa ideia, as respostas governamentais e institucionais parecem desvelar ainda mais suas rupturas, esfacelamentos e reparos.

Assim, opera-se a adoção da EAD não pelas suas características e potencialidades, mas pelo seu caráter eminentemente técnico de permitir a continuidade do ensino. Não se trabalha em uma lógica recomendada pela EAD, mas em uma precarização do seu modelo como forma de oferecer uma resposta imediata em um cenário de muitas mudanças. Aspectos motivacionais em relação à manutenção do ensino e propostas de discussão sobre os caminhos futuros da educação dão espaço à ideia da transposição. Assim, permitir a continuidade do ensino parece ser uma resposta mais adaptativa nesse momento do que permitir reflexões essenciais na produção da educação em nosso país.

Outro ponto relevante, integrado ao anterior, foi o tempo, em sua cronologia mesmo, das jornadas de trabalho que se ampliaram. É de conhecimento que o trabalho docente nas universidades públicas reflete a vocação dessas instituições para desenvolver atividades de ensino, pesquisa e extensão universitária, além da sua gestão que cabe ao corpo técnicoadministrativo e aos docentes. A transposição do ensino presencial para o "não presencial" produziu um dilatamento do tempo requerido para preparação e execução de atividades de ensino. Ademais, a sensação de caminhar no escuro ganha contornos importantes, justamente pela inabilidade de gestores educacionais pensarem os cotidianos institucionais e as relações de trabalho a partir das escalas, conforme apontado anteriormente. Nesse sentido, o oferecimento de cursos de curta duração, webconferências, web-seminários, tutoriais, materiais educativos e outros não pareceu dar conta do degrau atropelado e das suas reverberações no trabalho docente.

Em síntese, o que se quer destacar são as condições de trabalho docente em sua dimensão didático-pedagógica, operacional, domiciliar e sua convivência com as outras demandas nas áreas de pesquisa, extensão universitária e gestão - 
além da vida pessoal que segue seu curso. Tratam-se de aspectos a serem considerados, uma vez que as universidades públicas, cumprindo seu papel social, têm sido ainda mais demandadas e têm respondido à sociedade em tempos de pandemia e das múltiplas crises por ela criadas ou adensadas. Neste sentido é necessário indagar o "custo humano" dessas respostas desde o ponto de vista dos trabalhadores (Ribeiro et al., 2021; Ribeiro et al., 2020).

Diante desse panorama, tem-se estimulado o uso das metodologias assíncronas, pois permitem ao estudante acessar o conteúdo e estudar no momento em que julgue mais pertinente, respeitando os seus tempos e a sua autonomia diante do processo educativo e, no contexto da pandemia, o ajuste às condições domiciliares. Assim, entre as estratégias mais frequentes encontram-se as videoaulas, os fóruns e também questionários que podem ser respondidos pelo estudante no momento de maior conveniência.

Atualmente, o que se observa é a tentativa de privilegiar encontros, ainda que os mesmos sejam virtuais. Aventa-se que o contexto da pandemia, pelo fato de a maioria das pessoas estarem em situação de distanciamento e isolamento social, permitiria que a EAD se tornasse um espaço de encontro. Assim, o que anteriormente era compreendido como uma flexibilização passou a ser considerado uma das poucas formas de encontro possíveis diante da realidade vivida.

Nessa argumentação, portanto, a EAD parece ter ocupado uma posição diferente: se antes era uma alternativa para um encontro presencial e espacial que não era possível, agora passa a ser uma potencialidade para esse encontro que só se pode dar de modo virtual. Por isso, o incentivo aos métodos síncronos que estabelecem essa relação de proximidade com as pessoas que estão conectadas a um mesmo tempo, mas em espaços distintos. A EAD, nessa acepção, tem se colocado a serviço desse encontro que, em contextos de formação interrompidos durante a pandemia, pode não apenas continuar, como também potencializar expressões mais afetivas, de maior tolerância e de maior empatia entre estudantes e professores, competências essas consideradas fundamentais na formação de recursos humanos em saúde.

Ao mesmo tempo, essas escolhas têm colocado o imperativo da negociação perene entre docentes e estudantes sobre os termos da relação e, nomeadamente, das condições materiais, relacionais e tecnológicas do seu acontecimento, tendo em vista o já exposto aqui. Nesse debate é importante que situemos diferentes campos do conhecimento e o modo como eles têm se posicionado em termos da educação diante da pandemia.

\section{EAD e a Formação em Enfermagem}

No contexto da formação em enfermagem, há que se recuperar a necessidade de não apenas apresentar a EAD como uma interface para uma metodologia ativa de ensino e aprendizagem, mas de toda uma discussão que diz respeito ao papel do profissional de enfermagem em nossa sociedade, sobretudo em um cenário pandêmico, em que tal atuação tem sido elencada como uma das profissões da chamada "linha de frente" de combate ao novo coronavírus (Bezerra, 2020; Jowsey et al., 2020). Em que pesem o maior destaque e o maior reconhecimento que esse profissional vem recebendo em função desse contexto de cuidado em saúde, há que se problematizar de que modo a continuidade dos processos formativos em enfermagem estão sendo discutidos ao longo da pandemia. E, nesse processo, o diálogo com a EAD passa a ser recuperado a partir dos posicionamentos anteriormente apresentados neste artigo.

Assim, a enfermagem é um campo do conhecimento e da prática que, apesar de ter produzido ao longo dos anos um vasto repertório ligado à EAD (Alves et al., 2015) e à possibilidade de incrementar a formação em enfermagem a partir desse modelo de ensino e aprendizagem, tem sido diretamente impactado pela pandemia. $\mathrm{O}$ ensino de enfermagem, desse modo, não pode ser apenas operacionalizado ou permitido a partir da ancoragem em ferramentas disponibilizadas pela EAD enquanto um sinônimo de inovação como anteriormente era defendido (Scorsolini-Comin et al., 2020).

O desafio que se delineia é mais complexo e envolve a necessidade de uma formação crítica que ultrapasse os modelos em que é oferecida. Assim, aventa-se que o cenário de uma EAD sinônima de uma transposição do ensino presencial, 
como criticado neste artigo, pode promover um ensino de enfermagem que desconsidere a sua complexidade e, consequentemente, a sua importância para a formação de profissionais que também possam se situar diante da pandemia. A depender do modo como o ensino superior em enfermagem se posicionar - o que tem sido diferente a cada realidade institucional - distintas possibilidades poderão emergir, tanto as que considerem a manutenção de uma formação crítica até mesmo aquelas que pressuponham a automatização da formação desses profissionais visando a um rápido acesso ao mercado de trabalho e ao combate à pandemia.

O ensino possibilitado pela EAD durante a pandemia deve constantemente permitir não apenas a realização de processos de ensino e aprendizagem considerados tradicionais ou esperados para a continuidade da formação, mas justamente potencializar uma discussão de suma importância na construção de recursos humanos em saúde que ultrapassem os conhecimentos técnicos, ou seja, que tragam em seus repertórios elementos que possam constantemente permitir o posicionamento e a reflexão (Scorsolini-Comin, 2020). Obviamente que esse desafio não compete apenas à EAD, mas à própria educação em enfermagem, o que legitima a necessidade de endereçar tais reflexões a docentes e gestores educacionais engajados na oferta desses cursos na pandemia e para além da mesma.

\section{Considerações Finais}

Este estudo teve como objetivo refletir sobre o modo por meio do qual a EAD tem sido sugerida e implementada como metodologia capaz de possibilitar a manutenção dos processos de ensino e aprendizagem em função do distanciamento social deflagrado como recomendação para a contenção da transmissão viral a partir da pandemia de COVID-19 no ano de 2020. Para tanto, recorreu-se à literatura especializada como um ponto de partida que, integrado à experiência em curso dos autores, permitiu levantar algumas questões tidas como críticas no contexto da atual pandemia e que requerem atenção da comunidade científica e da sociedade como um todo.

Nesse sentido, buscou-se problematizar a maneira como a EAD emergiu no cenário de crise agravado pela pandemia de COVID-19, colocando-se, para uns, como uma alternativa ou solução possível e, para outros, como desafios, atropelos, demandas e, notadamente, como um agravante de situações de iniquidades sociais preexistentes. Com isso, não se colocou a EAD como o problema, mas a maneira como ela tem sido acionada nos discursos e práticas governamentais e institucionais. Para tanto, a compreensão do problema a partir das variadas escalas que ele suscita mostrou-se teoricamente pertinente, uma vez que possibilitou elencar e refletir sobre as materialidades e performances produzidas nas experiências discente e docente nítido está que ficaram de fora outros agentes e coletivos que compõem o cotidiano universitário, como os técnicos administrativos.

Por fim, cumpre ressaltar o caráter não definitivo dessas reflexões e, a despeito disso, o desafio de pensar e de experimentar pensar o que nos ocorre neste momento histórico tão crítico. Esta reflexão tocou, assim, em questões importantes como o acesso a essas tecnologias por parte dos alunos, as condições de trabalho dos docentes nesse novo cenário, além das falhas estruturais do nosso sistema de ensino, quer seja em modelos presenciais, quer seja na EAD ou então nas metodologias não presenciais impostas na pandemia. Observa-se, por exemplo, que a ideia de transposição, como se a EAD fosse substitutiva à presencial, promove não apenas equívocos, como dificuldades de docentes e estudantes nesse processo.

No que tange à educação em enfermagem, pelo tempo em que a pandemia persistir, novos aprendizados podem emergir, o que deve ser acompanhado por todos os pesquisadores que se propõem a investigar de que modo esta área pode ser impactada ou então se beneficiar desse período para refletir sobre a formação de novos profissionais. A educação deve ser vista como uma construção coletiva que visa a oferecer respostas justamente a cenários de instabilidade como o atual. $\mathrm{O}$ compromisso com essas reflexões deve ser anterior à crise e mais profundo, contribuindo na produção de um mundo capaz de responder aos desafios apresentados e propor a elaboração das novas perguntas que serão endereçadas às gerações futuras e de 
novas potencialidades para a formação em enfermagem.

A partir das reflexões endereçadas neste presente ensaio recomenda-se que os estudos vindouros possam investigar a médio e longo prazos as repercussões do período pandêmico na educação superior. Esse processo deve considerar os diferentes atores envolvidos, como estudantes, professores e gestores, familiares e redes de apoio, assumindo perspectivas que não apenas registrem e mensurem impactos no ensino, na formação e no itinerário após a universidade, mas que se posicionem criticamente. Em relação à formação em enfermagem priorizada neste ensaio, torna-se fundamental acompanhar de que modo a aproximação deste curso com a EAD, anterior à pandemia, foi se desenvolvendo também com as transformações oportunizadas a partir de um circunscritor que atingiu fortemente o ensino presencial e a formação desses profissionais de saúde. Os critérios de presença e de distância não podem ser discutidos a partir de teorias educacionais somente, mas considerando a inscrição das mesmas em projetos políticos e para a formação superior no contexto brasileiro. Estudos que não se comprometam com esse posicionamento ou que não revelem tensionamentos nesse sentido podem produzir reflexões que apenas apontem cosmeticamente ajustes entre uns modelos educacionais e outros, desconsiderando o sistema sobre o qual essas práticas de ensino se desdobram e, de fato, corporificam-se.

\section{Agradecimentos}

Os autores agradecem à Escola de Enfermagem de Ribeirão Preto da Universidade de São Paulo pelo apoio institucional, à Coordenação de Aperfeiçoamento de Pessoal de Nível Superior (Capes) e ao Conselho Nacional de Desenvolvimento Científico e Tecnológico (CNPq) pelo financiamento das pesquisas realizadas pelos autores.

\section{Referências}

Alves, V. L. D. S., Bohomol, E., \& Cunha, I. C. K. O. (2015). Educação de pós-graduação em enfermagem à distância: Avaliação sob a perspectiva dos discentes. Acta Paulista de Enfermagem, 28, 139-145. https://doi.org/10.1590/1982-0194201500024

Bezerra, I. M. P. (2020). State of the art of nursing education and the challenges to use remote technologies in the time of corona virus pandemic. Journal of Human Growth and Development, 30(1), 141-147. http://pepsic.bvsalud.org/scielo.php?script=sci_arttext\&pid=S0104-12822020000100018\&lng=pt\&nrm=iso

Castioni, R., Melo, A. A. S. D., Nascimento, P. M., \& Ramos, D. L. (2021). Universidades federais na pandemia da Covid-19: Acesso discente à internet e ensino remoto emergencial. Ensaio: Avaliação e Políticas Públicas em Educação, 29, 399-419. https://doi.org/10.1590/S0104-40362021002903108

Chick, R. C., Clifton, G. T., Peace, K. M., Propper, B. W., Hale, D. F., Alseidi, A. A., \& Vreeland, T. J. (2020). Using technology to maintain the education of residents during the COVID-19 pandemic. Journal of Surgical Education, 77(4), 729-732. https://doi.org/10.1016/j.jsurg.2020.03.018

Conselho Nacional de Secretários da Saúde-CONAS. (2021). Painel Nacional: COVID-19. Conselho Nacional de Secretários da Saúde-CONAS. Brasília: Autor. Disponível em: https://www.conass.org.br/painelconasscovid19/

Grossi, M. G., \& Kobayashi, R. M. (2013). A construção de um ambiente virtual de aprendizagem para educação a distância: Uma estratégia educativa em serviço. Revista da Escola de Enfermagem da USP, 47, 756-760. http://dx.doi.org/10.1590/S0080-623420130000300033

Dias, É., \& Pinto, F. C. F. (2020). A educação e a Covid-19. Ensaio: Avaliação e Políticas Públicas em Educação, 28, 545-554. https://doi.org/10.1590/S0104-40362019002801080001

Freitas, R. F., Ramos, D. S., Freitas, T. F., Souza, G. R. D., Pereira, É. J., \& Lessa, A. D. C. (2021). Prevalência e fatores associados aos sintomas de depressão, ansiedade e estresse em professores universitários durante a pandemia da COVID-19. Jornal Brasileiro de Psiquiatria, 70, 283-292. https://doi.org/10.1590/0047-2085000000348

Gaia, R. D. S. P., Silva V., A., Pereira, J. A. G., \& Scorsolini-Comin, F. (2021). Ações afirmativas como garantia e direito à educação da população negra no Brasil. Educação: Teoria e Prática, 31(64), e17[2021]. https://doi.org/10.18675/1981-8106.v31.n.64.s14647

Jowsey, T., Foster, G., Cooper-Ioelu, P., \& Jacobs, S. (2020). Blended learning via distance in pre-registration nursing education: A scoping review. Nurse Education in Practice, 44, 102775. https://doi.org/10.1016/j.nepr.2020.102775

Magalhães, R. C. D. S. (2021). Pandemia de covid-19, ensino remoto e a potencialização das desigualdades educacionais. História, Ciências, SaúdeManguinhos, 28, 1263-1267. https://doi.org/10.1590/S0104-59702021005000012

Oliveira, M. A. N. (2007). Educação à Distância como estratégia para a educação permanente em saúde: Possibilidades e desafios. Revista Brasileira de Enfermagem, 60, 585-589. https://doi.org/10.1590/S0034-71672007000500019

PAHO - Pan American Health Organization. (2021). Histórico da pandemia de COVID-19. Washington: Author. Disponível em: 
Research, Society and Development, v. 11, n. 1, e59411125458, 2022

(CC BY 4.0) | ISSN 2525-3409 | DOI: http://dx.doi.org/10.33448/rsd-v11i1.25458

https://www.paho.org/pt/covid19/historico-da-pandemia-covid-19

Patias, N. D., Von Hohendorff, J., Cozzer, A. J., Flores, P. A., \& Scorsolini-Comin, F. (2021). Mental health and coping strategies in undergraduate students during COVID-19 pandemic. Trends in Psychology, 29, 414-433. https://doi.org/10.1007/s43076-021-00069-z

Ribeiro, B. M. S. S., Rossato, L., \& Scorsolini-Comin, F. (2021). Burnout em docentes do ensino superior no período da pandemia da COVID-19: Reflexões com estudantes de enfermagem. Revista Thema, 20, 239-251. https://doi.org/10.15536/thema.V20.Especial.2021.239-251.1908

Ribeiro, B. M. S. S., Scorsolini-Comin, F., \& Dalri, R. C. M. B. (2020). Ser docente en el contexto de la pandemia de COVID-19: Reflexiones sobre la salud mental. Index de Enfermería, 29(3), 137-141. Disponível em: https://scielo.isciii.es/scielo.php?pid=S1132-12962020000200008\&script=sci_arttext\&tlng=en

Ribeiro, B. M. S. S., Scorsolini-Comin, F., Santos, S. V. M., \& Dalri, R. C. M. B. (2022). Brazilian nursing in pandemic times and the bicentennial of Florence Nightingale. Revista Brasileira de Enfermagem, 75, e20210081. https://doi.org/10.1590/0034-7167-2021-0081

Rouquayrol, M. Z. (2003). O processo epidêmico. In M. Z. Rouquayrol \& N. Almeida Filho, N. (Orgs.). Epidemiologia \& Saúde. $6^{\mathrm{a}}$ ed. Rio de Janeiro: MEDSI, p. 123-148.

Santos, G. M. R. F. D., Silva, M. E. D., \& Belmonte, B. D. R. (2021). COVID-19: Emergency remote teaching and university professors' mental health. Revista Brasileira de Saúde Materno Infantil, 21, 237-243. https://doi.org/10.1590/1806-9304202100S100013

Sartori, A. S. (2002). Educação a Distância: Novas práticas pedagógicas e as tecnologias da informação e da comunicação Revista Linhas, 3(2). Disponível em: https://periodicos.udesc.br/index.php/linhas/article/view/1192

Scorsolini-Comin, F. (2021). Projeto de pesquisa em ciências da saúde: guia prático para estudantes. Petrópolis: Editora Vozes.

Scorsolini-Comin, F. (2020). Programa de tutoría con estudiantes de enfermería en el contexto de la pandemia de COVID-19 en Brasil. Index de Enfermería, 29(1-2), 79-83. Disponível em: https://scielo.isciii.es/scielo.php?pid=S1132-12962020000100019\&script=sci_arttext\&tlng=pt

Scorsolini-Comin, F., Melo, L. P. D., Rossato, L., \& Gaia, R. D. S. P. (2020). Distance learning in nursing training: reflections on the COVID-19 pandemic. Revista Baiana de Enfermagem, 34, e36929-e36929. http://dx.doi.org/10.18471/rbe.v34.36929

Scorsolini-Comin, F. (2013). Avaliação dos processos de ensino-aprendizagem em ações educacionais ofertadas a distância. Temas em Psicologia, 21(2), 335346. http://dx.doi.org/10.9788/TP2013.2-03

Segata, J. (2020). Covid-19: Escalas da pandemia e escalas da antropologia. Boletim Cientistas Sociais e o Coronavírus, 23. Disponível em: http://anpocs.com/images/stories/boletim/boletim_CS/Boletim_n2.pdf

Sontag, S. (1984). A doença como metáfora. Rio de Janeiro: Edições Graal. (Coleção Tendências, n. 6).

Tanaka, E. Z., Sartori, D. V. B., Ferreira, L. R., \& Bermejo, L. J. (2017). A educação a distância nos cursos de graduação em enfermagem: Aplicação e efetividade. Revista Online de Política e Gestão Educacional, 831-841. http://dx.doi.org/10.22633/rpge.v21.n.esp1.out.2017.10455

Vieira, V. B. R., \& Teo, C. R. P. A. (2018). O ensino a distância na formação em saúde: Uma revisão integrativa de literatura. Revista de Educação Popular, 17(1), 114-125. https://doi.org/10.14393/REP-v17n12018-art07

Warhadpande, S., Khaja, M. S., \& Sabri, S. S. (2020). The impact of COVID-19 on interventional radiology training programs: What you need to know. Academic Radiology, 27(6), 868-871. https://doi.org/10.1016/j.acra.2020.04.024 